Japan. J. Med. Sci. Biol., 33, 303-310, 1980

\title{
DETECTION OF MACAQUE CHORIONIC GONADOTROPIN IN THE PLACENTA OF THE CYNOMOLGUS MONKEY (MACACA FASCICULARIS)
}

\author{
Tooru FUJIWARA, Yuriko SUZAKI, Yasutoshi YAMADA \\ and Shigeo HONJO* \\ Department of Veterinary Science, National Institute of Health, Musashi-Murayama, \\ Tokyo 190-12, and *Tsukuba Primate Center for Medical Science, \\ National Institute of Health, Ibaragi 305, Japan
}

(Received, July 29, 1980. Accepted, October 21, 1980)

\begin{abstract}
SUMMARY: The biologically detectable period of macaque chorionic gonadotropin (mCG) was estimated by the mouse uterine weight method with 22 placentas of the cynomolgus monkey at various pregnancy stages. The hormone was detectable in the placental extracts of the 4th and 5 th week of gestation, but not in those of the 6 th week or later. This fact may be compatible with our previous finding that mCG was not detectable in urine after the 6th week of gestation in the cynomolgus monkey.
\end{abstract}

\section{INTRODUCTION}

Using the rhesus monkey, many investigators reported that macaque chorionic gonadotropin (mCG) could be detected in urine and blood only for a few weeks in the early period of pregnancy (Delfs, 1941; Hamlett, 1937; Tullner and Hertz, 1966; Tullner, 1968; van Wagenen and Simpson, 1955). As regards the urinary mCG of the cynomolgus monkey, we have confirmed the same trend as of the rhesus monkey (Fujiwara and Imamichi, 1966). On the other hand, Hobson (1972a) reported that the peak excretion of urinary mCG occurred 25-28 days after conception and that a small but detectable amount of mCG was excreted throughout the pregnancy period in the rhesus monkey. At the same time, he determined $\mathrm{mCG}$ in the placenta with a maximum concentration at term (Hobson, 1972b). In contrast to Hobson's findings, Hodgen et al. (1975) demonstrated that mCG could not be detected during the middle or late stage of gestation in the placenta, serum or urine of the rhesus monkey. The present investigation was performed to examine the placenta of the cynomolgus monkey for mCG at various stages of gestation by a bioassay method.

藤原 徹・須崎百合子・山田保利（国立予防衛生研究所 獣疫部） 本庄重男（国立予防衛生研究所 筑波医学実験用霊長類センター） 
TABLE I

Uterine weight and other findings in mice receiving the control specimen or the various stages of pregnancy

\begin{tabular}{|c|c|c|c|c|c|c|c|}
\hline \multirow{2}{*}{\multicolumn{4}{|c|}{ Specimen }} & & \multirow{2}{*}{$\begin{array}{l}\text { 1)2) } \\
\text { Body weight } \\
\text { of mice (g) }\end{array}$} & \multirow{2}{*}{$\begin{array}{l}\text { Uterine weight } \\
\text { of mice }(\mathrm{mg})\end{array}$} & \multirow[b]{2}{*}{$\begin{array}{l}\text { Ratio of uterine } \\
\text { to body weight } \\
(\times 1000)\end{array}$} \\
\hline & & & & & & & \\
\hline \multicolumn{4}{|c|}{ Saline } & 10 & $11.0 \pm 1.6$ & $13.3 \pm 2.8$ & $1.21 \pm 0.16$ \\
\hline \multicolumn{4}{|c|}{ hCG (1 $\mathrm{IU} / \mathrm{ml})$} & 10 & $12.1 \pm 1.1$ & $17.3 \pm 2.3^{*}$ & $1.43 \pm 0.14^{*}$ \\
\hline \multicolumn{4}{|c|}{$\mathrm{hCG}(2 \mathrm{IU} / \mathrm{ml})$} & 10 & $12.3 \pm 0.9$ & $20.0 \pm 3.3^{*}$ & $1.63 \pm 0.22^{*}$ \\
\hline \multicolumn{4}{|c|}{ hCG $(4 \mathrm{IU} / \mathrm{ml})$} & 10 & $12.8 \pm 1.0$ & $26.3 \pm 3 \cdot 7 * *$ & $2.06 \pm 0.18^{* *}$ \\
\hline \multicolumn{4}{|c|}{ Estradiol $(10 \mathrm{ng} / \mathrm{ml})$} & 10 & $12.4 \pm 0.9$ & $14.3 \pm 1.8$ & $1.15 \pm 0.11$ \\
\hline $12712^{5)}$ & $4^{6)}$ & $29^{6)}$ & $0.6^{7)}$ & 2 & 13.5 & $45.0 * *$ & $3.33^{* *}$ \\
\hline 12728 & 4 & 29 & 0.9 & 4 & $12.3 \pm 1.2$ & $32.3 \pm 4.5^{* *}$ & $2.64 \pm 0.32 * *$ \\
\hline 12929 & 4 & 29 & 0.5 & 2 & 10.3 & $39.0 * *$ & $3.81^{* *}$ \\
\hline 12811 & 5 & 36 & 2.9 & 10 & $12.6 \pm 1.0$ & $26.7 \pm 6.2^{* *}$ & 2. $10 \pm 0.34 * *$ \\
\hline 13624 & 6 & 43 & 4.4 & 10 & $11.8 \pm 1.4$ & $14.5 \pm 3.7$ & $1.22 \pm 0.20$ \\
\hline 12731 & 7 & 49 & 6.7 & 10 & $12.5 \pm 1.1$ & $13.9 \pm 2.1$ & $1.11 \pm 0.16$ \\
\hline 12732 & 7 & 50 & 6.9 & 10 & $13.1 \pm 0.9$ & $14.5 \pm 2.0$ & $1.11 \pm 0.13$ \\
\hline 12826 & 7 & 50 & 4.3 & 10 & $12.2 \pm 0.8$ & $14.0 \pm 1.5$ & $1.15 \pm 0.09$ \\
\hline 13239 & 8 & 56 & 8.6 & 10 & $11.8 \pm 0.9$ & $14.3 \pm 2.5$ & $1.21 \pm 0.15$ \\
\hline 13449 & 9 & 64 & 14.2 & 10 & $11.7 \pm 1.0$ & $13.2 \pm 2.9$ & $1.13 \pm 0.21$ \\
\hline 12143 & 10 & 70 & 16.5 & 10 & 12. $6 \pm 1.0$ & $14.7 \pm 1.9$ & $1.17 \pm 0.09$ \\
\hline 12146 & 10 & 71 & 21.2 & 10 & 12. $6 \pm 1.1$ & $14.4 \pm 2.1$ & $1.15 \pm 0.12$ \\
\hline 12235 & 10 & 70 & 20.3 & 10 & $12.4 \pm 1.0$ & $13.8 \pm 3.1$ & $1.11 \pm 0.20$ \\
\hline 11984 & 15 & 107 & 30.7 & 10 & $12.9 \pm 1.0$ & $15.0 \pm 1.1$ & $1.16 \pm 0.07$ \\
\hline 12133 & 15 & 105 & 45.3 & 10 & $11.6 \pm 1.0$ & $12.2 \pm 2.5$ & $1.06 \pm 0.21$ \\
\hline 12202 & 15 & 107 & 38.2 & 10 & $12.2 \pm 1.0$ & $14.7 \pm 1.4$ & $1.21 \pm 0.03$ \\
\hline 8391 & 20 & 142 & 60.6 & 10 & $11.2 \pm 1.1$ & $13.2 \pm 2.7$ & $1.17 \pm 0.17$ \\
\hline 11360 & 20 & 140 & 72.2 & 10 & $11.4 \pm 0.8$ & 12. $6 \pm 1.4$ & $1.11 \pm 0.08$ \\
\hline 12319 & 20 & 143 & 58.9 & 10 & $11.9 \pm 1.3$ & 13. $2 \pm 2.2$ & $1.11 \pm 0.13$ \\
\hline Y-16 & term & & 94.2 & 10 & $11.4 \pm 1.0$ & $12.7 \pm 1.6$ & $1.12 \pm 0.13$ \\
\hline $\mathrm{Y}-31$ & term & & 76.8 & 10 & $11.4 \pm 1.1$ & $12.4 \pm 2.1$ & $1.08 \pm 0.13$ \\
\hline W-13 & term & & 75.8 & 10 & $11.8 \pm 0.8$ & $12.4 \pm 1.8$ & $1.05 \pm 0.13$ \\
\hline
\end{tabular}

1) Weight on the day of autopsy

2) Mean \pm standard deviation

3) Value of the left ovary

4) Number of mice showing positive indication / Number of mice used

5) Monkey number.

\section{MATERIALS ANd Methods}

Monkey placenta: Twenty-two placentas used in this experiment were obtained from the cynomolgus monkeys conceived at our laboratory primate facility. The methods for judgment of an optimal mating time as well as for mating and pregnancy diagnosis were the same as described previously (Fujiwara et al., 1973; Honjo et al., 1975). The next day of mating was regarded as the first day of gestation. The routine methods of care and management of the 
extract of cynomolgus monkey placentas in

\begin{tabular}{|c|c|c|c|}
\hline 2)3) & 4) & 4) & 4) \\
\hline $\begin{array}{l}\text { Ovarian weight } \\
\text { of mice (mg) }\end{array}$ & $\begin{array}{l}\text { Opening } \\
\text { of vagina }\end{array}$ & $\begin{array}{l}\text { Findings } \\
\text { of ovaries }\end{array}$ & $\begin{array}{l}\text { Hydro- } \\
\text { metra }\end{array}$ \\
\hline $3.1 \pm 0.3$ & $0 / 10$ & $0 / 10$ & $0 / 10$ \\
\hline $3.7 \pm 0.7$ & $0 / 10$ & $0 / 10$ & $0 / 10$ \\
\hline $4.0 \pm 0.7^{*}$ & $10 / 10$ & fol. ; $10 / 10$ & $0 / 10$ \\
\hline $4.0 \pm 0.9^{*}$ & $10 / 10$ & fol. ; $10 / 10$ & $0 / 10$ \\
\hline $3.0 \pm 0.8$ & $0 / 10$ & $0 / 10$ & $0 / 10$ \\
\hline $5.55^{* *}$ & $2 / 2$ & cl. $; 2 / 2$ & $2 / 2$ \\
\hline $5.0 \pm 0.8^{* *}$ & $4 / 4$ & cl. ;4/4 & $1 / 4$ \\
\hline $4.5 * *$ & $2 / 2$ & cl. ;2/2 & $1 / 2$ \\
\hline $4.6 \pm 0.8^{* *}$ & $10 / 10$ & fol. ; $10 / 10$ & $0 / 10$ \\
\hline $2.8 \pm 0.6$ & $0 / 10$ & $0 / 10$ & $0 / 10$ \\
\hline $3.0 \pm 0.0$ & $0 / 10$ & $0 / 10$ & $0 / 10$ \\
\hline $2.9 \pm 0.3$ & $0 / 10$ & $0 / 10$ & $0 / 10$ \\
\hline $3.2 \pm 0.9$ & $0 / 10$ & $0 / 10$ & $0 / 10$ \\
\hline $3.1 \pm 1.0$ & $0 / 10$ & $0 / 10$ & $0 / 10$ \\
\hline $3.0 \pm 0.7$ & $0 / 10$ & $0 / 10$ & $0 / 10$ \\
\hline $3.6 \pm 0.7$ & $0 / 10$ & $0 / 10$ & $0 / 10$ \\
\hline $3.0 \pm 0.0$ & $0 / 10$ & $0 / 10$ & $0 / 10$ \\
\hline $2.8 \pm 0.4$ & $0 / 10$ & $0 / 10$ & $0 / 10$ \\
\hline $3.2 \pm 0.4$ & $0 / 10$ & $0 / 10$ & $0 / 10$ \\
\hline $2.5 \pm 0.5$ & $0 / 10$ & $0 / 10$ & $0 / 10$ \\
\hline $3.3 \pm 0.7$ & $0 / 10$ & $0 / 10$ & $0 / 10$ \\
\hline $2.9 \pm 0.6$ & $0 / 10$ & $0 / 10$ & $0 / 10$ \\
\hline $3.5 \pm 0.7$ & $0 / 10$ & $0 / 10$ & $0 / 10$ \\
\hline $2.9 \pm 0.7$ & $0 / 10$ & $0 / 10$ & $0 / 10$ \\
\hline $2.6 \pm 0.5$ & $0 / 10$ & $0 / 10$ & $0 / 10$ \\
\hline $3.1 \pm 0.7$ & $0 / 10$ & $0 / 10$ & $0 / 10$ \\
\hline $2.8 \pm 0.6$ & $0 / 10$ & $0 / 10$ & $0 / 10$ \\
\hline
\end{tabular}

6) Age of placenta; in weeks (left) and days (right) of gestation

7) Weight of placenta (g)

fol.; Follicle formation cl.; Corpus luteum formation

* $\mathbf{P}<0.05$ )

** $\mathrm{P}<0.01\}$ Significant difference from the saline control

monkeys were the same as already published from our laboratory (Fujiwara et al., 1974). Of the 22 samples, 19 were collected between the 4 th and the 20th week of gestation either by hystrectomy or by hysterotomy. Three samples each were obtained in the 4 th, 7 th, 10th, 15th and 20th week and one sample each in the 5th, 6th, 8th and 9th week of gestation. Weight and size of placentas were already reported (Fujiwara et al., 1978). The remaining three placentas were collected from females at term as soon as possible following normal vaginal deliveries. All the samples were kept at $-20 \mathrm{C}$ immediately after removal. 
Preparation of placental extract: After removal of the umbilical cord and membranes, the placenta was homogenized at $4 \mathrm{C}$ in a tissue homogenizer to make a $50 \%(\mathrm{w} / \mathrm{v})$ emulsion in saline. The emulsion was allowed to stand overnight at $4 \mathrm{C}$ and then centrifuged at 5,000 rpm for $30 \mathrm{~min}$. The supernatant was saved and the precipitate was resuspended in normal saline at $4 \mathbf{C}$ and recentrifuged. The second supernatant was added to the first one to make a final placental extract for the bioassay of mCG.
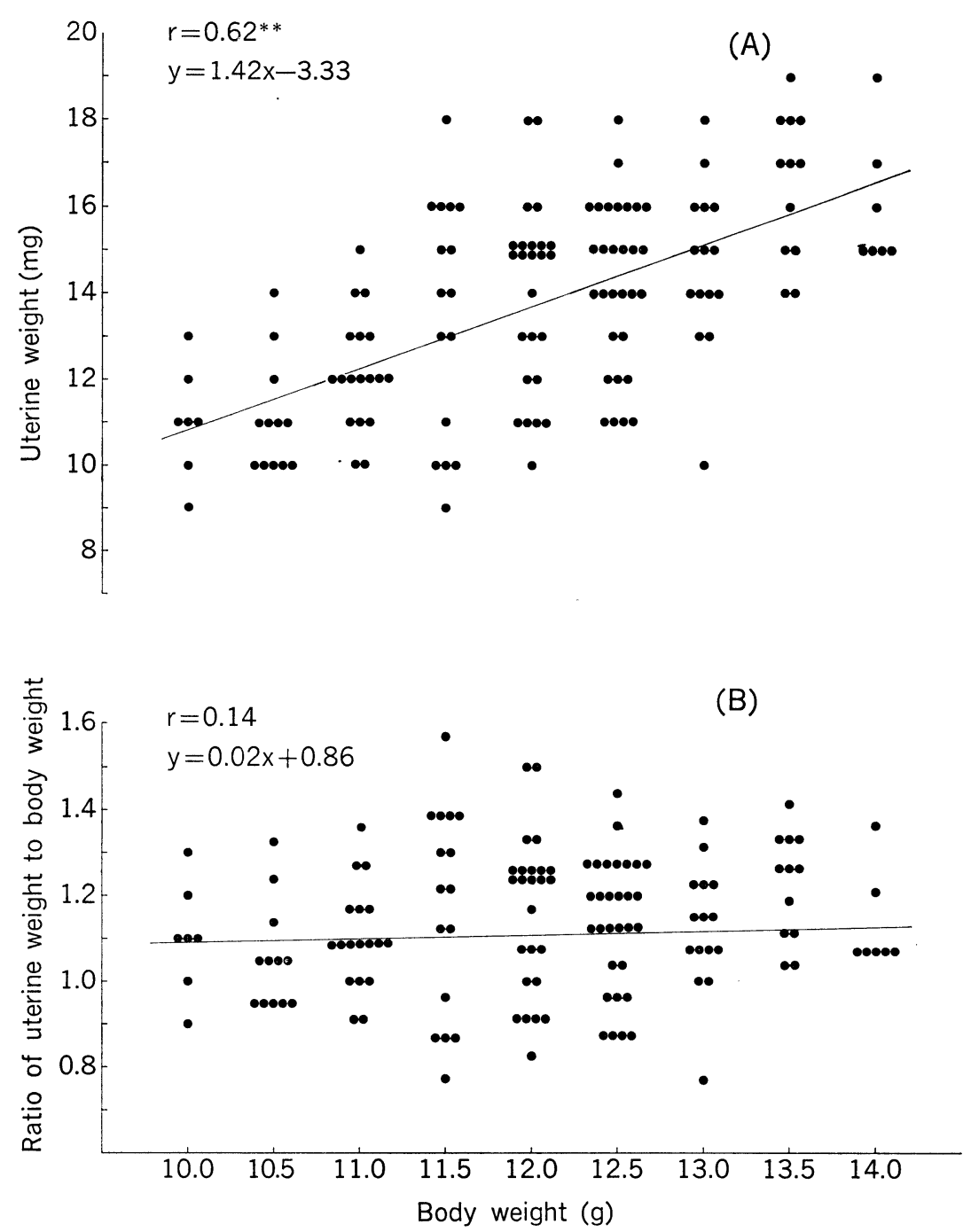

Fig. 1. Relationship between uterine and body weight in mice

A) Absolute values of uterine and body weight

B) Ratio of uterine and body weight 
Bioassay of $m C G$ : The uterine weight bioassay using immature mice was employed to determine mCG. Ten mice (YOK-ddy strain) of 20 days of age weighing 8 to $10 \mathrm{~g}$ were used for each specimen of placental extract except the mouse groups administered with the extracts of the 4th-week placentas (Table I). Each mouse was subcutaneously administered with $0.1 \mathrm{ml}$ of a specimen twice a day for 2 days, and then was sacrificed for autopsy $96 \mathrm{hr}$ after the first injection. Mice injected with saline or human chorionic gonadotropin (hCG; the 11th National Reference Standard hCG) served as controls. At autopsy, the body, uterus and ovaries were weighed and the ratio of uterine weight (mg) to body weight (g) was calculated. The opening of the vagina and the morphology of the ovaries as well as the occurrence of hydrometra were also examined.

Prior to the mCG bioassay, the relationship between the body weight and uterine weight was statistically analyzed with 142 mice of 25 days of age weighing 10 to $14 \mathrm{~g}$. In addition, another experiment was performed to check the possible estrogenic effect of the placental extract on the weight of the mouse uterus.

\section{RESULTS}

\section{Relationship between the Body and Uterine Weights of Mice}

As illustrated by Fig. 1, the coefficient of correlation between the body weight and uterine weight was statistically significant; the uterine weight of the 142 intact mice increased in parallel with their body weight. The average ratio of the uterine weight to the body weight [uterine weight $(\mathrm{mg}) /$ body weight $(\mathrm{g}) \times 1,000]$ showed little changes, ranging from 1.06 to 1.22 .

\section{Effects of Estrogen on Mouse Uterine Weight}

The concentration of total estrogens in the extracts of the placenta at term was estimated to be less than $3 \mathrm{ng}$ per $\mathrm{ml}$ of the extract by radioimmunoassay using antiserum to estrogens supplied by Dr. A. Abraham, University of California, Davis, CA, USA. The effect of $10 \mathrm{ng}$ of estradiol (Diosynth BV, Oss, Holland) in a l-ml oil suspension on the mouse uterine weight was examined by the same procedures as employed for mCG bioassay. As shown in Table I, there was no significant difference in the average uterine or ovarian weight between the groups of mice injected with estradiol and those with saline. From these results, the estrogenic effect of the monkey placental extract on mouse uterine weight was judged to be negligible in this assay system.

\section{Bioassay of Monkey Placental Extract}

All of the present experimental results are summarized in Table I.

The average uterine weight in three groups of mice administered with 1,2 and 4 IU of hCG in $1 \mathrm{ml}$ of saline were $17.3,20.0$ and $26.3 \mathrm{mg}$, respectively. These 
average values were 30,50 and $98 \%$ larger than the value of the saline control mice. The average ovarian weight of the hCG-injected mice was also larger than that of the saline control mice. These weight differences were statistically significant $(p<0.01)$. Besides, the opening of the vagina and the ovarian follicle formation were observed in mice administered with 2 or 4 IU of hCG, while none of such findings was observed in the saline- or estrogen-injected mice.

In three groups of mice injected with the samples collected in the 4th week of gestation, the average ratios of the uterine weight to the body weight were from 2.4 to 3.4 times as large as that of the saline control mice. Furthermore, the average ovarian weights of those groups of mice were 1.5-1.8 times as heavy as that of the saline control mice. Besides, all those mice showed the opening of vagina corpus luteum formation and hydrometra. The extract of the 5th-week placenta had also the effect to significantly increase the weights of the uterus and ovaries of the mouse $(\mathrm{p}<0.01)$. In the same mouse, the opening of the vagina and the ovarian follicle formation were noticed, whereas hydrometra was not observed. In 180 mice of 18 groups administered with samples extracted from 18 placental specimens collected between the 6th week of gestation and term, there were no positive findings suggestive of mCG effects.

\section{Discussion}

The present results clearly indicate that mCG was detectable in placental extracts only at the beginning of gestation period also in the cynomolgus monkey as was demonstrated in the rhesus monkey by Hodgen et al. (1975). The extracts from the 4th- and 5th-week placentas were positive for $\mathrm{mCG}$, inducing not only uterine and ovarian weight gains but also opening of the vagina, corpus luteum or follicle formations and hydrometra, in immature mice. The cynomolgus monkey placentas of the 4 th and 5 th week of gestation were so small in size that the mCG contents could not accurately be determined by the methods employed in this investigation. It was estimated by comparison with the data of hCG-injected groups that the 4 th-week placenta may contain mCG in a quantity equivalent to $4 \mathrm{IU}$ or more of hCG.

Hobson (1972b) reported that the concentration of mCG was lowest in early pregnancy both per gram and per placenta and reached a maximum level at term. The term values measured by Hobson were 4.7-24.0 IU hCG equivalents per gram of fresh tissue. However, the results of the present investigation suggest that the placenta of the cynomolgus monkey contains little or no mCG or less than 1 IU per gram of placenta at the middle and late stages of gestation. The results may substantiate our previous findings that mCG was not detectable in urine after the 6th week of gestation in the cynomolgus monkey (Fujiwara and Imamichi, 1966). Concerning the fluctuation of mCG during pregnancy, we consider that there may be no essential difference between the rhesus and cynomolgus monkeys. So, it is likely that the discrepancy between Hobson's result and ours may have been derived from differences in the evaluation of 
the results of mCG bioassay in immature mice.

The mouse uterine weight method has been used for the bioassay of chorionic gonadotropin. We consider that the results obtained by this bioassay system must be evaluated synthetically from the following three points; the uterine weight gain, the ratio of uterine weight to body weight, and other macroscopic findings of the uterus and ovaries. It is doubtful that Hobson evaluated his results in view of these points. Moreover, the uterine weight of the immature mouse increased in direct proportion to the increase of body weight (Fig. 1-A). On the other hand, the ratio of uterine weight to body weight remained almost constant in immature mice (Fig. 1-B). Wilson et al. (1970) reported that a ratio of the uterine weight to the body weight of 1.35 or greater was regarded as positive indication of the presence of $\mathrm{mCG}$ as a result of pregnancy. The present positive samples also showed the ratios higher than 1.5 without exception (Table I).

Generally speaking, there are many similar points in biological characteristics between human and macaque monkeys. However, the subtle differences between them, as shown in the results of the present study, should be taken into consideration.

\section{ACKNowledgement}

We wish to express our gratitude to Dr. T. Asano, Department of Veterinary Science of this institute, for the performance of radioimmunoassay of estrogens.

\section{REFERENCES}

Delfs, E. (1941): Serum chorionic gonadotropin in the rhesus monkey. Anat. Rec., 79, Suppl. 17. Fujiwara, T. ANd IMAmichi, T. (1966): Breeding of cynomolgus monkey as experimental animal. Japan. J. Med. Sci. Biol., 19, 225-226.

Fujiwara, T., Cho, F., Honjo, S. and Imaizumi, K. (1973): An index for the judgment of optimal mating time in female cynomolgus monkeys (Macaca fascicularis). Exptl. animals, 22, Suppl., $395-402$.

Fujrwara, T., Suzaki, Y., Yoshioka, Y. and Honjo, S. (1974): Hematological changes during pregnancy and postpartum period in cynomolgus monkeys (Macaca fascicularis). Exptl. Animals, 23, 137-146.

Fujiwara, T., Suzaki, Y. And Honjo, S. (1978): Weight and size of the placenta in cynomolgus monkeys (Maacca fascicularis). Japan. J. Med. Sci. Biol., 31, 365-369.

Hamletr, G. W. D. (1937): Positive Friedman tests in the pregnant rhesus monkey, Macaca mulatta. Am. J. Physiol., 118, 664-666.

Hobson, B. M. (1972a): New observations on the excretion of chorionic gonadotrophin during pregnancy in the rhesus monkey (Macaca mulatta). Folia Primat., 18, 463-468.

Hobson, B. M. (1972b): Gonadotrophin concentration in the placentae of man, the rhesus monkey and the marmoset. Folia Primat., 18, 35-40.

Hodgen, G. D., Niemann, W. H. and Tullner, W. W. (1975): Duration of chorionic gonadotrophin production by the placenta of the rhesus monkey. Endocrinology, 96, 789-791.

Honjo, S., Fujiwara, T. AND Cho, F. (1975): A comparison of breeding performance of individual cage and indoor gang cage systems in cynomolgus monkeys. p.98-105. In S. Kondo, M. Kawai and A. Ehara [eds.]. Comtemporary Primatology, Karger, Basel.

Tullner, W. W. ANd Hertz, R. (1966): Normal gestation and chorionic gonadotropin levels in the monkey after ovariectomy in early pregnancy. Endocrinology, 78, 1076-1078. 
TULLNER, W. W. (1968): Urinary chorionic gonadotropin excretion in the monkey (Macaca mulatta)-Early phase. Endocrinology, 82, 874-875.

van WAGENEN, G. AND Simpson, M. E. (1955): Gonadotrophic hormone excretion of the pregnant monkey (Macaca mulatta). Proc. Soc. Exptl. Biol. Med., 90, 346-348.

Wilson, J. M., Fradkin, R. And Hardman, A. (1970): Breeding and pregnancy in rhesus monkeys used for teratological testing. Teratology, 3, 59-70. 